\title{
Statin discontinuation: counterbalancing the benefits with the potential risks
}

Kosmas I. Paraskevas ${ }^{1}$, Sotirios Koupidis², Fotini Gentimi ${ }^{3}$, Alexandros A. Tzovaras ${ }^{4}$

\author{
1Department of Vascular Surgery, Red Cross Hospital, Athens, Greece \\ 2University of Athens Medical School, Athens, Greece \\ $3^{3} 2^{\text {nd }}$ Department of Pediatric Surgery, Aghia Sophia Children's Hospital, Athens, \\ Greece \\ ${ }^{4} 1^{\text {st }}$ Department of Oncology, Aghios Savvas Hospital, Athens, Greece
}

Submitted: 15 August 2011

Accepted: 18 September 2011

Arch Med Sci 2011; 7, 6: 1076-1077

DOI: 10.5114/AOMS.2011.26622

Copyright () 2011 Termedia \& Banach

Besides cholesterol lowering, statins exert several non-lipid (so-called "pleiotropic") actions [1-4]; statins improve vascular endothelial function and exert antithrombotic and anti-inflammatory effects [1, 2]. Statins are also associated with a reduced incidence of coronary risk and cardiovascular events [5-7].

A recent study demonstrated that statin withdrawal increased the risk of subarachnoid haemorrhage by $>60 \%$ compared with non-use (odds ratio (OR) 1.62; 95\% confidence interval (Cl) 0.96-2.73) and by $>2$-fold compared with current use (OR 2.34; 95\% Cl 1.35-4.05) [8]. An earlier study showed that, compared with continuous statin use, statin withdrawal is associated with an almost 3-fold increase in first-year mortality rates after an ischaemic stroke episode (hazard ratio (HR) 2.78; $95 \% \mathrm{Cl} 1.96-3.72$; $p=0.003$ ) [9]. Finally, a controlled randomized study showed that statin withdrawal at the time of admission for a hemispheric ischaemic stroke was associated with a 19-fold increase in the risk of early neurological deterioration compared with previous statin non-use (HR 19.01; 95\% Cl 1.96-184.09; $p<0.001$ ) [10]. It was proposed that, once initiated, statin treatment should not be interrupted except for a very good reason [11].

The inferior outcomes associated with statin withdrawal may be attributed to a "rebound" phenomenon [11]. Statins inhibit NAD(P)H oxidase and superoxide production and upregulate the expression and activity of endothelial nitric oxide synthase (eNOS) via inhibition of geranylgeranylation of RhoA and Rac1 GTPases [12]. RhoA negatively regulates eNOS and Rac1 contributes to $\mathrm{NAD}(\mathrm{P}) \mathrm{H}$-oxidase activation and superoxide production [12]. Withdrawal of statin treatment leads to an overshoot activation of RhoA and Rac1 with considerable effects on nitric oxide bioavailability, $\mathrm{NAD}(\mathrm{P}) \mathrm{H}$-oxidase activity, and superoxide production [12]. The net result is overt endothelial dysfunction and vasoregulatory dysfunction [11, 12].

Besides the studies showing an association between statin withdrawal with subarachnoid haemorrhage [8], mortality rates after an ischaemic stroke episode [9] and neurological deterioration after an ischaemic stroke episode [10], a contradictory report should also be mentioned [13]. This report underlines the increased incidence of intracranial haemorrhage associated with high statin dosage use in patients with a prior history of stroke [13]. A more recent study, however, failed to verify the association

\author{
Corresponding author: \\ Kosmas I. Paraskevas \\ MD, FASA \\ Department \\ of Vascular Surgery \\ Red Cross Hospital \\ 24, Al. Papagou Street \\ N. Iraklio 14122 \\ Athens, Greece \\ Phone: +30 6977776202 \\ Fax: +30 2103215792 \\ E-mail: \\ paraskevask@hotmail.com
}


between statin use in patients with a history of ischaemic stroke with an increased risk of intracranial haemorrhage [14]. Current evidence also indicates that statins should be discontinued in patients after a haemorrhagic stroke episode [15]. The 2011 Updated Society for Vascular Surgery guidelines for the management of carotid artery stenosis patients recommended statin use in all patients scheduled for carotid revascularization aiming at reducing low-density lipoprotein cholesterol (LDL-C) levels < $100 \mathrm{mg} / \mathrm{dl}$ [16]. Due to these controversial reports, in patients suffering an ischaemic stroke, the possibly increased risk of future intracranial haemorrhage should be counterbalanced with the expected cardiovascular benefits associated with statin use.

Ideally, the exact effects of statin withdrawal should be investigated in a prospective randomized trial. Given the uniform results from the reports performed so far, however [8-10], such a trial may never be carried out due to considerable ethical limitations. Physicians should ensure that patients not on statins initiate a statin immediately after a vascular event [11] or prior to vascular surgery [17]. More importantly, however, they should make sure that patients on routine statin use do not discontinue their treatment in order to avoid the occurrence of a first [8] (or recurrent) $[9,10]$ vascular event.

Unfortunately, there is evidence that many cardiovascular patients do not receive any lipid-lowering treatment [18]. Some physicians may be reluctant to prescribe lipid-lowering drugs in all patients, independent of their lipid levels. They should bear in mind that serum LDL-C levels $<70$ $\mathrm{mg} / \mathrm{dl}$ do not seem to affect the adrenal axis function in terms of cortisol production, which is mainly synthesized from cholesterol [19]. Thus, physicians may administer statins independently of the patient's lipid levels.

These data suggest an increased physician alertness for statin discontinuation in vascular patients.
ACE inhibitors alone and in combination on clinical outcome in patients with coronary heart disease. J Hum Hypertens 2004; 18: 781-8.

7. Athyros VG, Mikhailidis DP, Papageorgiou AA, et al.; GREACE Collaborative Group. Effect of atorvastatin on high density lipoprotein cholesterol and its relationship with coronary events: a subgroup analysis of the GREek Atorvastatin and Coronary-heart-disease Evaluation (GREACE) Study. Curr Med Res Opin 2004; 20: 627-37.

8. Risselada R, Straatman H, van Kooten F, et al. Withdrawal of statins and risk of subarachnoid hemorrhage. Stroke 2009; 40: 2887-92.

9. Colivicchi F, Bassi A, Santini M, Caltagirone C. Discontinuation of statin therapy and clinical outcome after ischemic stroke. Stroke 2007; 38: 2652-7.

10. Blanco M, Nombela F, Castellanos M, et al. Statin treatment withdrawal in ischemic stroke: a controlled randomized study. Neurology 2007; 69: 904-10.

11. Tziomalos K, Athyros VG, Mikhailidis DP. Statin discontinuation: an underestimated risk? Curr Med Res Opin 2008; 24: 3059-62.

12. Endres M, Laufs U. Effects of statins on endothelium and signaling mechanisms. Stroke 2004; 35 (11 Suppl 1): 2708-11.

13. Flaster M, Morales-Vidal S, Schneck MJ, Biller J. Statins in hemorrhagic stroke. Expert Rev Neurother 2011; 11: 1141-9.

14. Hackam DG, Austin PC, Huang A, et al. Statins and intracerebral hemorrhage: a retrospective cohort study. Arch Neurol 2011 Sep 12 [Epub ahead of print].

15. Westover MB, Bianchi MT, Eckman MH, Greenberg SM. Statin use following intracerebral hemorrhage: a decision analysis. Arch Neurol 2011; 68: 573-9.

16. Ricotta JJ, Aburahma A, Ascher E, Eskandari M, Faries P, Lal BK. Updated Society for Vascular Surgery guidelines for management of extracranial carotid disease. J Vasc Surg 2011; 54: e1-31.

17. Paraskevas KI, Liapis CD, Hamilton G, Mikhailidis DP. Can statins reduce perioperative morbidity and mortality in patients undergoing non-cardiac vascular surgery? Eur J Vasc Endovasc Surg 2006; 32: 286-93.

18. Vulic D, Loncar S, Krneta M, et al. Risk factor control and adherence to treatment in patients with coronary heart disease in the republic of Sprska, Boznia and Herzegovina in 2005-2006. Arch Med Sci 2010; 6: 270-5.

19. Sezer K, Emral R, Corapcioglu D, Gen R, Akbay E. Effect of very low LDL-cholesterol on cortisol synthesis. J Endocrinol Invest 2008; 31: 1075-8.

\section{References}

1. Paraskevas KI, Stathopoulos V, Mikhailidis DP. Pleiotropic effects of statins: implications for a wide range of diseases. Curr Vasc Pharmacol 2008; 6: 237-9.

2. Tziomalos K, Athyros VG, Karagiannis A, Mikhailidis DP. Endothelial function, arterial stiffness and lipid lowering drugs. Expert Opin Ther Targets 2007; 11: 1143-60.

3. Xu M, Yuan G, Wei F. Effect of atorvastatin in patients with chronic heart failure - insights from randomized trials. Arch Med Sci 2010; 6: 866-73.

4. You DQ, Lin SG, Chen JY, et al. Effect of atorvastatin therapy on borderline vulnerable lesions in patients with acute coronary syndrome. Arch Med Sci 2011; 7: 433-9.

5. Athyros VG, Kakafika Al, Papageorgiou AA, et al.; GREACE Study Collaborative Group. Lipids 2007; 42: 999-1009.

6. Athyros VG, Mikhailidis DP, Papageorgiou AA, et al.; GREACE Study Collaborative Group. Effect of statins and 